\title{
Identifikasi Citra Tulisan Tangan untuk Menentukan Karakter Kepribadian Introvert atau Extrovert dengan Metode LS Classifier
}

\section{Identification Image Handwriting to Determine Introvert or Extrovert Character Personality Using LS Classifier Methode}

\author{
Rusbianto $^{1}$, Indah Susilawati ${ }^{2}$ \\ 1,2Program Studi Teknik Informatika, Fakultas Teknologi Informasi, Universitas Mercu Buana Yogyakarta, \\ Jl. Wates Km. 10 Yogyakarta 55753, Indonesia \\ Email: rusby.maktech@gmail.com ${ }^{1}$, indah@mercubuana-yogya.ac.id ${ }^{2}$
}

\begin{abstract}
ABSTRAK
Tulisan tangan datang dari karakter (pembawaan) dan otak sehingga tulisan tangan seseorang mempunyai ciri khas. Semua teks pada dasarnya sama, berawal dari gerakan-gerakan psikomotorik yang dilakukan seseorang. Apapun bentuk teks tulisannya, grafologi memiliki peranan untuk menganalisis dari beberapa bentuk yang bisa dilihat. Grafologi secara garis besar dapat dilihat dari besar kecilnya tulisan, gaya tulisan, kemiringan tulisan, jarak antar kata atau antar huruf, ukuran tulisan, dan tekanan tulisan. Penelitian ini membahas tentang bagaimana sebuah perangkat lunak mengenali sebuah pola citra digital berupa pengenalan tulisan tangan yang menggunakan metode Least Square Classifier untuk menentukan karakter kepribadian introvert atau extrovert. Citra tulisan tangan dilakukan segmentasi untuk mendapakan feature vector rerata tekanan tulisan. Sementara centroid dan bounding box memberikan ciri jarak antar huruf dan jarak spasi. Pengujian dilakukan terhadap 20 sample tulisan tangan dengan image inputan berformat *.bmp. Feature vector pengujian kemudian dilakukan klasifikasi dalam dua kelas yaitu: jika masuk kelas -1 disimpulkan sebagai extrovert dan jika masuk kelas 1 disimpulkan sebagai introvert. Kinerja identifikasi karakter kepribadian dengan metode Least Square Classifier dalam penelitian ini mencapai $80 \%$.
\end{abstract}

Kata kunci: bounding_box ; extrovert; feature_vector; introvert; least_square_classifier.

\begin{abstract}
Handwriting comes from character (carriage) and brain so that someone's handwriting has its own characteristics. All text is basically the same, starting from psychomotor movements that someone does. Whatever the text form, graphology has a role to analyze from some visible form. Graphology in general can be seen from the size of writing, writing style, the slope of writing, the distance between words or between letters, the size of writing, and writing pressure. This thesis discusses how a software recognizes a digital image pattern in the form of handwriting recognition using Least Square Classifier method to determine introvert or extrovert personality characters. Handwritten image is done segmentation to get the feature vector average of writing pressure. While the centroid and bounding box gives the characteristic distance between letters and spacing. The test was conducted on 20 handwriting samples with the image format *.bmp. Feature of vector testing is then classified into two classes: if entering class -1 is concluded as extrovert personality and if class 1 is concluded as introvert personality. Identification perfomance using Least Square Classifier methode reached 80\%.
\end{abstract}

Keywords: bounding_box; extrovert; feature_vector; introvert; least_square_classifier.

\section{PENDAHULUAN}


Pengenalan karakter sudah banyak diteliti oleh berbagai kalangan, salah satunya pengenalan tulisan tangan. Grafologi merupakan cabang ilmu pengetahuan psikologi yang dipakai untuk menginterpretasikan karakter dan kepribadian seseorang melalui tulisan tangan. Ketika menulis, terjadi kolaborasi antara gerakan motorik dan kondisi psikis, hal ini disebut psikomotor. Pada hakikatnya saat menulis, seseorang sedang mengadakan kontak emosi dan intelektualitas. Pengenalan karakter seseorang melalui tulisan tangannya, biasanya secara manual dilakukan oleh seorang grafolog yang berpengalaman, diperlukan misalnya dalam rangka tes psikologi.

Penelitian ini dilakukan untuk membangun suatu aplikasi identifikasi karakter seseorang berdasarkan tulisan tangannya, yang ditujukan sebagai alat bantu untuk identifikasi secara otomatis berbantuan komputer.

Pengenalan tulisan tangan terbagi menjadi dua kategori, yaitu online system dan offline system. Pada online system, data tulisan tangan diperoleh melalui suatu perangkat khusus seperti touch screen pada tablet $P C$ dan smartphone. Pada penelitian ini, dibangun pengenalan tulisan tangan berupa offline system yang tidak memerlukan suatu perangkat khusus melainkan bekerja pada citra tulisan tangan yang diambil melalui scanner atau sejenisnya. Tulisan tangan dapat dijadikan suatu citra (image) yang dapat diolah dengan metode image processing kemudian diklasifikasikan dalam beberapa pola untuk mengidentifikasikan jenisnya. Bagaimana desain suatu perangkat lunak terhadap citra tulisan tangan yang dapat secara langsung menginterpretasikan tulisan tangan untuk menentukan karakter kepribadian seseorang sebagai introvert (kepribadian tertutup) atau ekstrovert (kepribadian terbuka).

\section{TINJAUAN PUSTAKA}

Pengenalan tulisan tangan sudah banyak diteliti berbagai kalangan. Supatman (2010) melakukan penelitian dengan judul Identifikasi Citra Tulisan Tangan dengan Metode Alihragam Gelombang Singkat Untuk Memprediksi Kematangan Emosional. Dalam penelitian ini membahas penggunaan metode alihragam gelombang singkat sebagai preprocessing citra yaitu dengan dekomposisi citra 2D maka dihasilkan citra akhir dan divectorkan sebagai feature vector. Feature vector selanjutnya dijadikan vector masukan Learning
Vector Quantization untuk memprediksi kematangan citra tes dari tulisan tangan yang baru.

Kanta (2013) dalam penelitian dengan judul Pengenalan Pola Huruf Hijaiyah Tulisan Tangan Menggunakan Logika Fuzzy dengan Jaringan Syaraf Tiruan Backpropagation. Metode pengenalan yang diangkat dalam tugas akhir ini menggunakan logika fuzzy dimana sebuah huruf dibagi menjadi beberapa bagian yang disebut segment untuk menemukan parameter titik awal, titik ujung dan titik percabangan. Sedangkan untuk proses klasifikasi menggunakan metode jaringan syaraf tiruan propagasi-balik (backpropagation).

Adeney dan Korenberg (2000) dengan judul "Target Adaptation to Improve the Performance of Least-Squared Classifiers", Queen's University, penelitian ini bertujuan untuk menjelaskan sebuah metode untuk memilih target yang sedemikian rupa sehingga mengurangi efek yang tidak diinginkan dari kriteria jumlah error kuadrat.

Parametasari, Adiwijaya dan Atmaja (2012) dalam Pengenalan Huruf Alfabet Tulisan Tangan Mengunakan Modified Direction Feature dan Jaringan Saraf Tiruan Backpropagation. Sistem pengenalan huruf alfabet dengan menggunakan Modified Direction Feature dan jaringan saraf tiruan Backpropagation menghasilkan kesimpulan bahwa kedua metode ini dapat digunakan untuk mengenali tulisan tangan berupa huruf alfabet.

Sulaeman, Harsani dan Qur'ania (2016) dalam Identifikasi Karakter Manusia Melalui Tulisan Tangan Dengan Mengunakan Metode Analisis Texture dan Median Filter Berbasis $W e b$. Tujuan dari penelitian identifikasi karakter manusia melalui tulisan tangan adalah untuk mengetahui karakter seseorang berdasarkan ilmu grafologi, menggunakan metode analisis tekstur untuk mengetahuai nilai ekstraksi ciri dari citra tulisan tangan, serta memperbaiki dan mengambil nilai tengah pada citra tulisan tangan menggunakan metode median filter, proses identifikasi karakter menggunakan metode jarak Euclidean.

\section{METODOLOGI PENELITIAN}

Langkah-langkah dalam identifikasi tulisan tangan untuk menentukan kepribadian terbuka (extrovert) dan kepribadian tertutup (introvert) dalam penelitian ini ditunjukkan dalam blok diagram Gambar 1. 


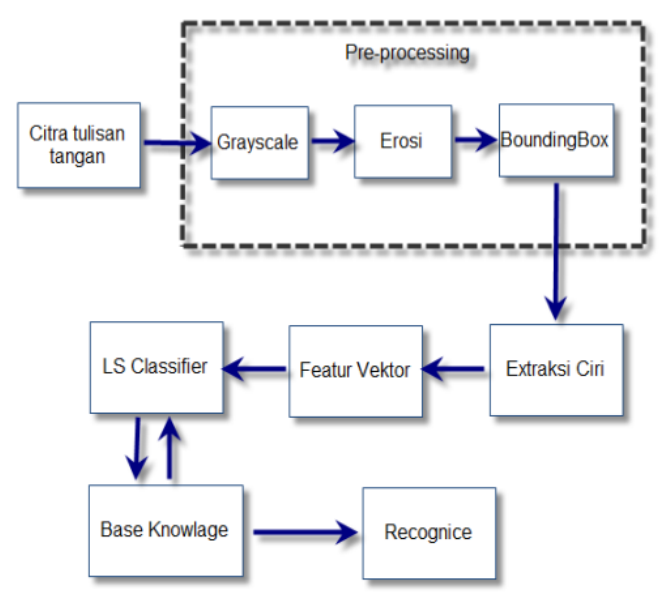

Gambar 1. Diagram blok penelitian

\subsection{Akusisi}

Proses akusisi data dilakukan dengan mengambil sample tulisan tangan pada kertas putih A4 80 gram yang diberikan ruang 12 x 10 $\mathrm{cm}$ ditulis menggunakan pensil $2 \mathrm{~B}$ dengan jumlah data 50 orang. Dari tulisan tangan tersebut di buat citra dengan jalan melakukan scanning terhadap tulisan tangan menjadi file *bmp. dengan resolusi 200 dpi. Selain menscan tulisan tangan tersebut dengan bantuan psikolog di Fakultas Psikologi, Universitas Mercu Buana Yogyakarta untuk menginterprestasikan tulisan tangan tersebut menjadi kelompok kepribadian tertutup (introvert) dan kepribadian terbuka (extrovert) yang digunakan sebagai data pelatihan (learning).

\subsection{Resizing}

Citra hasil akusisi kemudian dilakukan resize untuk mengubah ukuran lebar dan tinggi sebuah citra. Proses resize menjadi penting karena ukuran yang terdapat pada citra terlalu kecil dan tidak selalu sama oleh karena itu agar tidak ada perbedaan ukuran dan mengganggu kinerja sistem untuk proses lebih lanjut. Pada penelitian in citra di resize menjadi 100 x 500 piksel untuk memudahkan pemrosesan citra pada tahap penelitian dan pengenalan.

\subsection{Grayscale}

Proses segmentasi citra mengunakan grayscale dan threshold. Salah satu tahapan segmentasi yang digunakan pada tahapan dalam sistem pengenalan adalah mengubah citra warna menjadi citra grayscale, hal ini digunakan untuk menyederhanakan model citra. Citra berwarna terdiri dari 3 layer matrik yaitu $R$-layer, $G$-layer dan B-layer. Segmentasi citra dengan teknik peng-ambangan intensitas (threshold). Nilai yang lebih kecil daripada nilai ambang diperlakukan sebagai area pertama dan yang lebih besar daripada atau sama dengan nilai ambang dikelompokkan sebagai area yang kedua. Area yang tidak ada tulisan tangan diubah menjadi hitam dan tulisan yang terdeteksi diubah menjadi warna putih.

\subsection{Erosi}

Proses ini akan menghasilkan objek yang menyempit (mengecil). Lubang pada objek citra juga akan tampak membesar seiring menyempitnya batas objek tersebut. Proses erosi membandingkan setiap pixel citra masukan dengan nilai pusat tapis (kernel) dengan cara melapiskan (superimpose) tapis dengan citra sehingga pusat tapis tepat dengan posisi pixel citra yang diproses. Jika semua pixel pada tapis sama dengan semua nilai pixel objek (foreground) citra maka pixel masukan di set nilainya dengan nilai pixel foreground, bila tidak maka masukan pixel di beri nilai pixel background.

\subsection{Bounding Box}

Citra hasil erosi selanjutnya dilakukan proses bounding box. Proses yang digunakan dalam identifikasi tulisan tangan ini mengunakan kotak pembatas berorientasi pada objek. Dimana objek yang terdeteksi pada angka 1 akan dicari titik center-nya, kemudian dari titik center tersebut dicari areanya. Area yang sudah diketahui kemudian diberi kotak pembatas (bounding box). Dari proses bounding box kemudian diambil cirinya, dari ciri-ciri yang sudah diambil dijadikan feature vector. Proses bounding box dapat dilihat pada gambar 2.

\subsection{Least Square Classifier}

Identifikasi citra tulisan tangan dalam penelitian ini menggunakan metode Least Square Classifier (LS Classifier) adalah sebuah metode klasifikasi yang mengestimasi vector parameter $\mathrm{w}$ dan mengambil classifier linear yang terbaik berdasarkan vector parameter $\mathrm{w}$. Pada classifier ini tidak diperlukan asumsi sebaran data yang linear separable. 


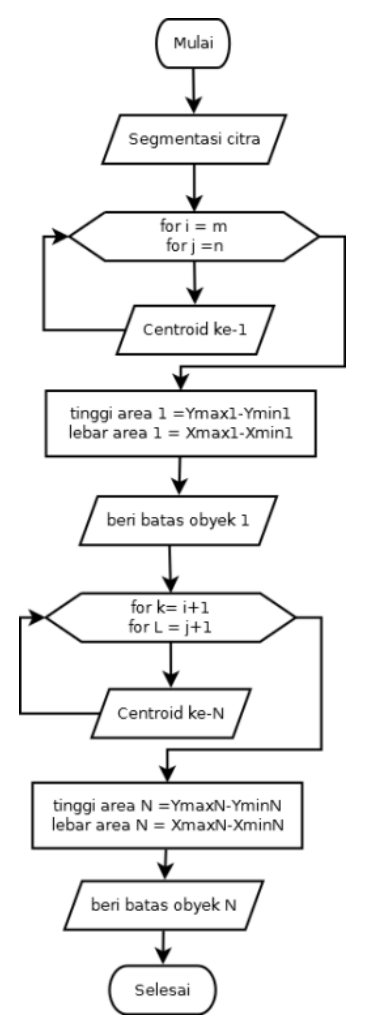

Gambar 2. Flowchart bounding box

\section{Keterangan:}

- Segmentasi citra $=$ citra yang didapat dari proses segmentasi

- $\mathrm{m}=$ panjang vector baris

$-\mathrm{n}=$ panjang vector kolom

$-\mathrm{x}=$ vector matriks baris baru

$-\mathrm{y}=$ vector matriks baris baru

- Xmax $=$ vector baris citra terjauh sumbu y

- Xmin $=$ vector baris citra terdekat sumbu $\mathrm{x}$

- Ymax = vector kolom citra terjauh sumbu y

- $\quad$ Ymin $=$ vector kolom citra terdekat sumbu $\mathrm{X}$

- $\mathrm{N}=$ banyak data

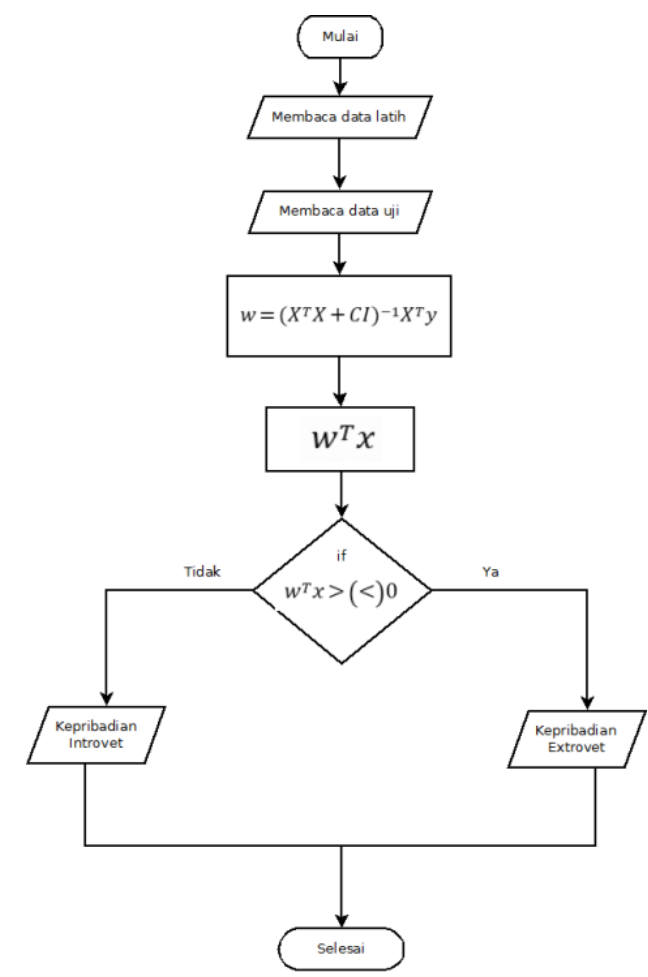

Gambar 3. Least square classifier flowchart

Keterangan:

- $\quad w=$ nilai bobot

- $\quad X=$ data latih yang sudah diaugmentasi

$-x=$ data uji yang sudah diaugmentasi

- $y=$ vector yang menyatakan kelas masing-masing data latih

Proses pelatihan Least Square Classifier dalam penelitian ini menggunakan 30 data citra yang dikelompokkan dalam 2 kelas, setiap kelas terdiri dari 15 data citra. Data tersebut akan digunakan untuk mengestimasi besaran w. Dengan $C$ dipilih sama dengan 0 atau $C=0, X$ adalah vector data pelatihan, $I$ adalah matriks identitas, dan $y$ adalah vector yang menyatakan kelas masing-masing data pelatihan yang bersesuaian. Sehingga formula $\mathrm{w}$ menjadi persamaan 1 .

$$
w=\left(X^{T} X\right)^{-1} X^{T} y
$$

Setelah hasil tersebut diperoleh, maka akan digunakan untuk mengidentifikasikan $d u$ (data uji) dengan menggunakan persamaan 2 .

$$
w^{T} x>(<) 0
$$

Yang artinya jika $w^{T} x>0$ maka data masuk kelas +1 , dan jika $w^{T} x<0$ data masuk kelas 1. Untuk mengidentifikasikan data uji, maka 
terlebih dahulu data uji diaugmentasi menjadi satu dimensi lebih tinggi. Mengimplementasikan persamaan (2), w dikalikan dengan data $\mathrm{x}$, apabila hasilnya kurang dari 0 maka masuk ke kelas -1 (extrovert), apabila hasil lebih dari 0 maka masuk ke kelas 1 (introvert). Nilai w pada pengujian ditunjukan pada Tabel 1.

Tabel 1. Nilai W

\begin{tabular}{clc}
\hline No & \multicolumn{1}{c}{ Ciri } & Nilai $w$ \\
\hline 1 & Tekanan tulisan & 0.0001 \\
\hline 2 & Rerata tekanan tulisan & 0.0202 \\
\hline 3 & Jarak antar huruf & -0.4903 \\
\hline 4 & $\begin{array}{l}\text { Std deviasi jarak antar } \\
\text { huruf }\end{array}$ & 0.0153 \\
\hline 5 & Jarak spasi & -0.3341 \\
\hline 6 & Std deviasi jarak spasi & 0.1679 \\
\hline
\end{tabular}

\section{PEMBAHASAN}

Citra hasil akusisi kemudian melalui proses pre-processing, citra tulisan tangan dilakukan resize 100 x 500 agar citra yang dilakukan segmentasi hasilnya maksimal. Setelah proses resize, citra diambil cirinya dengan menggunakan grayscale untuk mengambil 2 ciri yaitu tekanan tulisan dan rerata piksel. Proses pemgambilan ciri selanjutnya dilakukan setelah citra tulisan tangan dilakukan proses erosi dan bounding box. Citra tulisan tangan akan diberi kotak pembatas setiap citra yang terbaca nilai 1 . Setiap huruf akan dicari titik center-nya, kemudian setelah diketahui titik pusatnya, citra akan diberi kotak pembatas sesuai lebar dan tinggi citra tersebut. Dari proses bounding box ini akan diambil 4 ciri yaitu: jarak antar huruf, standar deviasi jarak antar huruf, jarak spasi, dan standar deviasi antar spasi.

Dalam proses pelatihan dan pengujian, data yang digunakan adalah file gambar berukuran 100 x 500 piksel dalam format.*bmp. Data yang digunakan untuk pelatihan yaitu 30 data citra. Akusisi citra tulisan tangan ditunjukan pada Gambar 4.

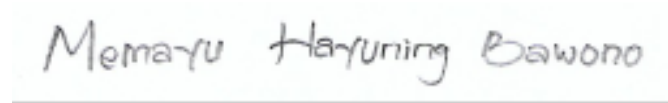

Gambar 4. Citra tulisan tangan

Hasil citra erosi ditunjukkan pada Gambar 5.

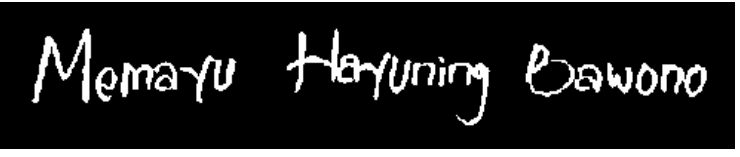

Gambar 5. Citra hasil erosi

Citra hasil bounding box ditunjukkan pada Gambar 6.

\section{Memay, Hayenung Bawend}

Gambar 6. Hasil bounding box

Data citra kemudian diekstraksi dan disimpan dalam bentuk *.txt yang dijadikan data pelatihan. Setelah mendapatkan nilai $w$, data pengujian diklasifikasi menggunakan Least Square Classifier. Lalu data pengujian yang sudah diaugmentasi dikalikan dengan $w$, apabila nilai $\mathrm{z}<0$ maka masuk kelas -1 (extrovert) dan apabila nilai $\mathrm{z}>0$ maka masuk kelas 1 (introvert). Pengujian menggunakan 20 data tulisan tangan diperoleh hasil 16 data dapat diidentifikasi dengan benar, sedangkan 4 data yang lain terjadi kesalahan atau error. Dengan demikian, dalam penelitian ini dicapai kinerja setinggi $80 \%$.

\section{KESIMPULAN}

Penelitian Identifikasi Citra Tulisan Tangan untuk Menentukan Karakter Kepribadian Introvert atau Extrovert dengan Metode LS Classifier menghasilkan kesimpulan sebagai berikut:

1. Kinerja sistem identifikasi tulisan tangan dengan metode Least Square Classifier dengan memakai 6 ciri yaitu tekanan tulisan, rerata piksel, jarak antar huruf, standar deviasi jarak antar huruf, jarak spasi dan standar deviasi jarak spasi. Keenam ciri tersebut dijadikan feature vector untuk diklasifikasikan ke dalam dua kelas, kelas kepribadian introvert dan kelas kepribadian extrovert.

2. Hasil pengujian dengan 20 data tulisan tangan adalah 16 dapat diidentifikasi dengan benar sedangkan yang 4 terjadi kesalahan. Persentase dari hasil pengujian tersebut adalah $80 \%$. 


\section{UCAPAN TERIMA KASIH}

Dengan segala kerendahan hati, penulis menyampaikan ucapan terimakasih yang mendalam kepada:

1. Bapak Supatman, S.T., M.T., selaku Dekan Fakultas Teknologi Informatika, Universitas Mercu Buana Yogyakarta.

2. Mas Ishaq Matondang atas bantuannya untuk menginterprestasikan data tulisan tangan.

\section{DAFTAR PUSTAKA}

Adeney, \& Korenberg. (2000). Target Adaptation to Improve the Performance of Least Sguared Classifiers.

Amend, K., \& Ruiz, K. (2014). Dasar-dasar lengkap Analisis Tulisan Tangan. Yogyakarta: Pustaka Pelajar.

Kadir, A., \& Susanto, A. (2013). Teori dan Aplikasi Pengolahan Citra. Yogyakarta: Andi.

Kanta. (2013). Pengenalan Pola Huruf Hijaiyah Tulisan Tangan Menggunakan Logika Fuzzy dengan Jaringan Syaraf Tiruan Backpropagation.

Moorey, T. (2008). Amazing You - Grafologi. Jakarta: Matahati.
Parametasari, Adiwijaya, \& Atmaja. (2012). Pengenalan Huruf Alfabet Tulisan Tangan Mengunakan Modified Direction Feature dan Jaringan Saraf Tiruan Backpropagation.

Prasetyo, E. (2012). Pengolahan Citra Digital dan Aplikasinya Menggunakan Matlab. Yogyakarta: Andi.

Prasetyono. (2012). Bedah Lengkap Grafologi. Yogyakarta: Diva Press.

Qur'ani, D. Y., \& Rosmalinda, S. (2010). Jaringan Syaraf Tiruan Learning Vector Quantization Untuk Aplikasi Pengenalan Tanda Tangan.

Sulaeman, Harsani, \& Qur'ania. (2016). Identifikasi Karakter Manusia Melalui Tulisan Tangan Dengan Mengunakan Metode Analisis Texture dan Median Filter Berbasis Web.

Supatman. (2010). Identifikasi Citra Tulisan Tangan Menggunakan Metode Alihragam Gelombang Singkat Untuk Menentukan Kematangan Emosional. SNPPTI 2010 (hal. 74-80). Jakarta: Universitas Mercu Buana.

Yulistiono, S., \& Manga, J. (2016). Komputasi Proses Teknik Kimia Menggunakan MATLAB. Yogyakarta: DEEPUBLISH. 